\title{
Association of a Functional Inducible Nitric Oxide Synthase Promoter Variant with Susceptibility to Infantile Cerebral Palsy
}

Torres-Merino S ${ }^{1}$, Moreno-Sandoval HN² , del Rocio Thompson-Bonilla $\mathbf{M}^{2}$, Gonzalez-Barrios JA² ${ }^{*}$, Leon-Chavez BA ${ }^{3}$ and Martinez-Fong $\mathrm{D}^{4}$

${ }^{1}$ Neuropediatric Department, Comprehensive Rehabilitation Center "CRIT-Telethon", Via Gustavo Baz Prada No. 225, State of Mexico, CP 54015, Mexico ${ }^{2}$ Genomic Medicine Laboratory, Regional Hospital "First of October", ISSSTE, Av. No. 1669 National Polytechnic Institute, Mexico City, CP 07760, Mexico ${ }^{3}$ Academy of Biochemistry and Molecular Biology, Faculty of Chemistry, BUAP,14 south and Av. San Claudio, 72570, Puebla, Pue, Mexico

${ }^{4}$ Department of Physiology, Biophysics and Neurosciences, CINVESTAV, Av. No. 2508 National Polytechnic Institute, Mexico City, CP 06760, Mexico

\begin{abstract}
Background: Recently it has been shown an increase in the interleukin 1 beta and nitrite levels in cerebrospinal fluid as a primary response of the immature brain to oxygen deprivation in newborns that suffered perinatal asphyxia, $30 \%$ to $40 \%$ of these patients later develop neurological abnormalities incluiding cerebral palsy. Formerly was shown that an increased enzyme activity of NOS2 is responsible for the increase in nitrite levels in cerebrospinal fluid. The NOS2A gene has a polymorphic microsatellite (CCTTT) located at $-2.6 \mathrm{~Kb}$ from the gene promoter. The expansion of this microsatellite to 13 or 14 repeats increases transcription of the NOS2A gene and triples the nitric oxide level under hypoglycemia and hypoxia conditions. The study aim was shown that the expansion of $-2.6 \mathrm{~Kb}$ CCTTT microsatellite in the NOS2 gene promoter, constitutes a risk factor for developing cerebral palsy in newborns that suffered perinatal asphyxia
\end{abstract}

Methods: Genomic DNAs purified from peripheral leukocytes of 48 ICP patients and 57 healthy children, the (CCTTT)n microsatellite expansion were amplified by PCR, purified from agarosa gel in micro-column method and sequenced using genomelab methods development kit cycle sequencing dye terminator in an automated CEQ8000 sequencer.

Results: The presence of a 14-repeat is significantly associated with infant cerebral palsy (Fisher $P$ value $=0.0122$ ). Multivariate analysis adjusted for age and sex confirmed the association with an increased risk of developing infant cerebral palsy (odds ratio, 1.78; 95\% confidence interval, 1.150-2.752; $P=0.01$ ).

Conclusions: Our findings suggest that an expansion to 14 repeats of the CCTTT microsatellite plays a key role in the development of cerebral palsy in children that suffered perinatal asphyxia.

Keywords: Perinatal hypoxia; Single nucleotide polymorphism; Asphyxia susceptibility

\section{Introduction}

The hypoxic ischemic encephalopathy (HIE) secondary to perinatal asphyxia, affects a 1.5 to $5 \%$ of newborns; unfortunately $10 \%$ to $20 \%$ of infants with moderate HIE die and $30 \%$ to $40 \%$ develop neurological abnormalities, whilst $50 \%$ of infants with severe HIE, die and the remainder develop neurological conditions [1]. To our knowledge, the reason why some children that suffered perinatal asphysxia develop infant cerebral palsy while other children with similar clinical histories develop memory and learning difficulties but no motor disabilities remains unknown. Infantile cerebral palsy (ICP) is a neurological disease resulting from damage of the immature brain in newborn children, clinically it is a non-progressive brain insult that produces permanent and progressive secondary postural and movement disorders [2] and induces long-term complications such as muscle hypotrophy, deformities in the skull and spine [3]. In Mexico there are approximately 500,000 diagnosed cases of CP, be the leading cause of death in children from 5 to 14 years old [4] and it is the most common cause of physical disability in children throughout the world [5]. The main clinical spectrum of ICP includes quadriparesis, hemiparesis, and diparesis that affect upper and lower limbs to varying degrees. The therapeutic management of ICP is targeted at the lesions caused on the central nervous system, bone deformations and muscle hypotrophy [6]. The initial inflammatory response in the immature brain as a result of a traumatic birth can be mapped from proteins and metabolites that participate in inflammation and oxidative stress $[7,8]$. The main oxidative metabolite which is produced in the inflammatory response is the Nitric oxide (NO), it is a multifunctional molecule that has been found to participate in neurotransmission [9], regulation of vascular tone as a vasodilator [10], and apoptosis [11], as well as in certain human pathologies such as Alzheimer's [12] and Parkinson's disease [13]. NO is produced by three NOS (Nitric Oxide Synthase) isoforms; neuronal (NOS1 or nNOS), inducible (NOS2 or NOS2A) and endothelial (NOS3 or eNOS) which produce nitric oxide by oxidation of L-arginine [14]. NOS1 and NOS3 are encoded and expressed by constitutive genes. NOS2 is encoded by an inducible gene that activates in inflammatory and pathological conditions. Other authors have described that the promoter region of the NOS2 gene may influence the transcriptional activity of the gene. Various microsatellites have been associated with the susceptibility to develop specific pathologies. For example there is a pentanucleotide polypyrimidine microsatellite, CCTTT (rs3833912) [15] at position $-2.6 \mathrm{~Kb}$ in the NOS2A gene promoter which has been associated with malaria [16], pulmonary arterial hypertension $[17,18]$, diabetic retinopathy [19] and nephropathy [20], dementia with Lewy bodies [12], nasal polyposis and atopy [21,22]. Recently, studies

*Corresponding author: Juan Antonio González-Barrios, Genomic Medicine Laboratory, Regional Hospital "First of October", ISSSTE, Av. No. 1669 National Polytechnic Institute, Mexico City, CP 07760, Mexico, Tel: 523892532060; E-mail: jantgonzalez@issste.gob.mx

Received July 15, 2015; Accepted August 14, 2015; Published August 17, 2015

Citation: Torres-Merino S, Moreno-Sandoval HN, Thompson-Bonilla DR, Gonzalez-Barrios JA, Leon-Chavez BA, et al. (2015) Association of a Functional Inducible Nitric Oxide Synthase Promoter Variant with Susceptibility to Infantile Cerebral Palsy. J Neurol Disord 3: 248. doi:10.4172/2329-6895.1000248

Copyright: () 2015 Torres-Merino S, et al. This is an open-access article distributed under the terms of the Creative Commons Attribution License, which permits unrestricted use, distribution, and reproduction in any medium, provided the original author and source are credited. 
Citation: Torres-Merino S, Moreno-Sandoval HN, Thompson-Bonilla DR, Gonzalez-Barrios JA, Leon-Chavez BA, et al. (2015) Association of a Functional Inducible Nitric Oxide Synthase Promoter Variant with Susceptibility to Infantile Cerebral Palsy. J Neurol Disord 3: 248. doi:10.4172/2329-6895.1000248

Page 2 of 4

have described differences in induction of NOS2A depending on the number of CCTTT repeats, importantly, (CCTTT) 14 allele has greater activity than the (CCTTT) 9 , (CCTTT) 12 , and (CCTTT) 15 alleles; also numerous cytokine responsive elements have been found in the promoter and regulatory region of NOS2A, with a number of them residing in the $-4 \mathrm{~Kb}$ region upstream of the transcriptional initiation site $[23,24]$. The -2.6 (CCTTT) 13,14 and 15 alleles of the microsatellite in the NOS2A gene respond to IL- $1 \beta$ drastically increasing NO production under hypoxic and inflammatory conditions [25]. Together, these observations point towards whether the functional -2.6(CCTTT) $\mathrm{n}$ pentanucleotide microsatellite in the NOS2A gene is associated with the development of cerebral palsy in patients with clinical history of perinatal asphyxia.

\section{Methods}

\section{Subjects}

A total of 105 children arranged into two groups were studied in a case control study; 47 patients with cerebral palsy and clinical history of perinatal hypoxia-ischemia and low APGAR $(<7$ at 5 min) matched to 57 healthy children as controls all living in the Mexico City metropolitan area. All patients underwent treatment at the neuropediatric's department of the Centro de Rehabilitación Integral Teleton (CRIT) in Tlalnepanltla, Estado de México. Clinical manifestations of cerebral palsy have been described previously [26,27]. All individuals were between 7-14 years old with a mean age of cerebral palsy patients and control group at 14.3 and 12.6 years, respectively. This study was approved by the institutional review board of the Centro de Rehabilitación Integral "Teleton" and the Hospital Regional "Primero de Octubre" and informed written consent was obtained from all patients' parents.

\section{Genotyping}

Peripheral blood $(200 \mu \mathrm{L})$ obtained by means of puncture with a contact activated lancet (BD Microtainer, NJ, USA) was collected in a tube containing K2 EDTA as an anticoagulant (BD Microtainer, NJ, USA). Once the samples were taken, they were immediately stored at $4^{\circ} \mathrm{C}$ using plates of cryoconservation gel and hermetic receiving containers for their transfer to the Genomic Medicine Laboratory of the Regional Hospital "Primero de Octubre" ISSSTE. The samples were processed for the genomic DNA extraction by using Ilustra microcolumns (Blood Genomic Mini Prep Spin Kit) of General Electric Healthcare (Piscataway, NJ, USA). Polymerase chain reaction (PCR) amplification of the corresponding fragments of the NOS2A promoter region, including the (CCTTT)n microsatellite site, was performed in a 9700 thermal cycler (Applied Biosystems) using the following primers: 5'-ACC CCT GGA AGC CTA CAA CTG CAT- 3' and 5'-GCC ATC GCA CCC TAG CCT GTC TCA-3'. The PCR reaction was performed in a final volume of $25 \mu \mathrm{L}$ including PCR buffer $1 \mathrm{X}, 100 \mu \mathrm{M} \mathrm{dNTPa}$, $200 \mu \mathrm{M}$ of each primer, $500 \mu \mathrm{M} \mathrm{MgSO}_{4}, 0.2 \mathrm{U}$ Pfx DNA polymerase and $20 \mathrm{ng}$ of genomic DNA. Cycling conditions included an initial denaturing of $95^{\circ} \mathrm{C}$ for 5 minutes followed by 35 cycles at $95^{\circ} \mathrm{C}$ for 30 $\mathrm{s}, 65^{\circ} \mathrm{C}$ for $30 \mathrm{~s}$ and $72^{\circ} \mathrm{C}$ for 1 minute; and a final extension at $72^{\circ} \mathrm{C}$ for 10 minutes. In order to determine if there was contamination, negative controls were included in each PCR reaction. Samples were analyzed by electromagnetic electrophoresis in Horizon 20.25 chamber (Whatman) on $2 \%$ agarose gels at $100 \mathrm{~V}$ and $400 \mathrm{~mA}$ run for 2 hours, waiting a size bands from $141 \mathrm{bp}$ to $236 \mathrm{bp}$ for alleles with 1 and 20 repeats of the CCTTT microsatellite, expecting a delta of $5 \mathrm{bp}$ for each additional microsatellite. To ensure that heterozygous alleles were correctly identified, bands were recovered and extracted using the QIAquick Gel
Extraction Kit (QIAGEN, Hilden, Germany). Once purified the DNA was used in sequencing PCR using genomelab methods development kit cycle sequencing dye terminator (beckman coulter, galway, ireland) and afterwards cleaned using the agencourt cleanseq kit (Beckman Coulter, Galway, Ireland). Products were then subjected to direct sequencing electrophoresis in an automated CEQ8000 Beckman DNA sequencer (Beckman Coulter, Galway, Ireland). The resulting chromatograms were aligned and viewed with Chromas 2.3 software (Technelysium Pty Ltd, Ewantin, Australia) using the GenBank NOS2A reference genomic sequence accession number AF440785.

\section{Statistical analyses}

To test for differences in frequency distributions of genotypes between groups the $\mathrm{X}^{2}$ test was used. Age and sex adjusted odds ratios (ORs) and 95\% confidence intervals (CI) were calculated by logistic regression analysis. In all statistical tests $\mathrm{P}<0.05$ was considered to be statistically significant. Data analysis was carried out using the PSPP 0.6.0 (PSPP) open source software (GNU licence) and graphical data representation was done with QtiPlot 0.9.6.2 open source software (GNU licence).

\section{Results}

\section{Selection of study subjects}

Forty-eight patients for a genomic study of infant cerebral palsy (ICP) were included based on four inclusion criteria: (1) Term babies with more than 36 weeks gestation; (2) Demonstrable history of perinatal asphyxia in neonatal medical records; (3) No metabolic diseases; and (4) No brain malformations. Thus, all individuals included in the patient group had been diagnosed with infant cerebral palsy by clinical, radiological and electroencephalographic criteria. These individuals were matched by age and gender to 57 apparently healthy control individuals in whom neurological diseases had been excluded by clinical neuropediatric evaluation.

\section{Perinatal asphyxia history}

The cerebral palsy group was composed of $67.7 \%$ of men and $32.3 \%$ of women, while control group was composed by $42.1 \%$ of men and $57.9 \%$ of women. The Apgar score in patients with infant cerebral paralysis was $3 \pm 1.48,5 \pm 1.31$ and $6 \pm 0.5$ at 1,5 and 10 minutes after birth respectively, whereas in the control group these were $8 \pm 1,9.5$ \pm 0.5 and 10 at 1,5 and 10 minutes after birth respectively (Figure 1 ).

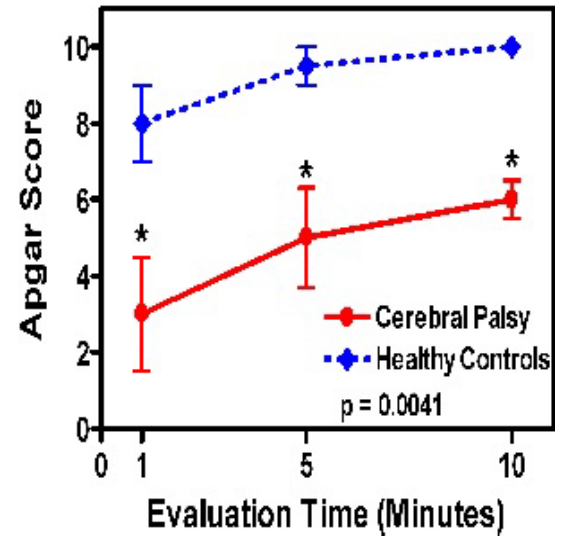

Figure 1: Time course of APGAR score. All APGAR scores ratings were obtained from the data in the medical records of the participants in the CRIT Tlalnepantla, with prior informed parental consent. 
Citation: Torres-Merino S, Moreno-Sandoval HN, Thompson-Bonilla DR, Gonzalez-Barrios JA, Leon-Chavez BA, et al. (2015) Association of a Functional Inducible Nitric Oxide Synthase Promoter Variant with Susceptibility to Infantile Cerebral Palsy. J Neurol Disord 3: 248. doi:10.4172/2329-6895.1000248

Page 3 of 4

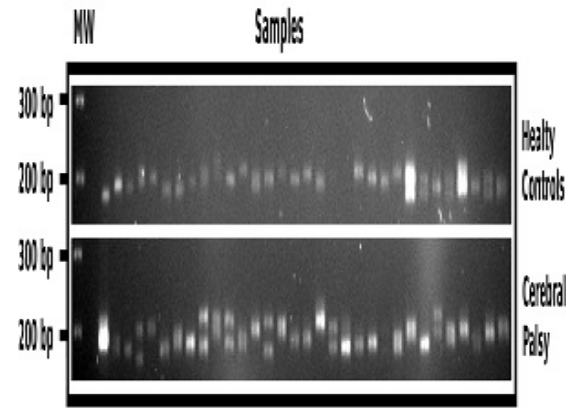

Figure 2: Polymorphic alleles of CCTTTn microsatellite in the promoter region of NOS2a gene. Representative electrophoretic pattern in agarose gel $2.5 \%$ prestained with ethidium bromide, the photograph shows the vast (CCTTT) n microsatellite variability in the promoter region $-2.6 \mathrm{~Kb}$ which regulate the transcription of the inducible nitric oxide synthase type A (iNOSa or NOS2A) by interleukin- $1 \beta$.

\begin{tabular}{|c|c|c|c|c|c|}
\hline \multirow{2}{*}{ Genotype } & \multirow{2}{*}{$\begin{array}{c}\text { (CCTTT) } \\
\mathbf{n}\end{array}$} & $\begin{array}{c}\text { Gealthy } \\
\text { Controls }\end{array}$ & $\begin{array}{c}\text { Cerebral } \\
\text { Palsy }\end{array}$ & \multirow{2}{*}{$\boldsymbol{p}$ Value } & OR (95\% CI) \\
\hline Short & $\mathrm{n} \leq 12$ & $38(66.7 \%)$ & $27(57.5 \%)$ & $0.0001^{*}$ & $0.3328(0.245-0.451)$ \\
\hline \multirow{2}{*}{ Pathological } & $\mathrm{n}=13$ & $6(10.5 \%)$ & $5(10.6 \%)$ & 0.1846 NS & $0.6053(0.311-1.178)$ \\
\cline { 2 - 5 } & $\mathrm{n}=14$ & $7(12.3 \%)$ & $10(21.3 \%)$ & $0.0122^{*}$ & $1.779(1.150-2.752)$ \\
\hline Long & $\mathrm{n} \geq 15$ & $6(10.5 \%)$ & $5(10.6 \%)$ & 0.2652 NS & $0.7036(0.405-1.222)$ \\
\hline
\end{tabular}

Table 1: General alleles frequency of -2600 (CCTTT)n microsatellite of NOS2A promoter in patients with cerebral palsy secondary to hypoxia-ischemia perinatal.

\section{Electrophoretic analysis}

Electrophoretic mobility on agarose gels of PRC products of the -2600 (CCTTT)n microsatellite revealed the presence of different sizes of maternal and paternal alleles with high molecular weight variability in the Mexican population which does not allow direct sequencing analysis from genomic DNA (Figure 2).

\section{Allele frequency of the CCTTT microsatellite polymor- phisms}

A total of 13 different alleles (5 to 17 repeats) were found in healthy individuals and cerebral palsy patients. The frequency distribution of microsatellite alleles followed a normal distribution ranging from $6.4 \%$ for 3 repeats, $2.1 \%$ for 1 repeat with a peak of $31.9 \%$ for 12 repeats (Figure 1). Short-form alleles ( $\leq 12$ repeats) were found to be present in $57.5 \%$ (27 out of 47 ) of cerebral palsy patients and $66.74 \%$ ( 38 out of 57 ) of healthy controls; also, the physiological form 13 repeats, was found to be present in $\approx 10 \%$ of both cerebral palsy and healthy control groups, with 5 and 6 patients respectively, while the 14-repeat long allele was present in $21.3 \%$ of the cerebral palsy patients and $12.3 \%$ of healthy controls (10 and 7 individuals, respectively). Long form alleles ( $\geq 15$ repeats) were found to be present in $\approx 10 \%$ ( 4 out of 48 ) of cerebral palsy patients and $\approx 10 \%$ ( 6 out of 57 ) of healthy controls (Table 1 ).

Statistical analysis revealed that the short form do not have correlation with cerebral palsy development (OR=0.3328, 95\% $\mathrm{CI}=0.245-0.451, P=0.822$ ) while the 14 -repeat allele was significantly associated with the development of cerebral palsy in patients with a history of perinatal asphyxia $(\mathrm{OR}=1.779,95 \% \mathrm{CI}=1.150-2.752$, $P=0.0122)$. Linear regression analysis showed that the risk of developing cerebral palsy significantly increases as the repeat number in an individual increases $(\mathrm{OR}=1.29, P=0.023)$.

\section{Discussion}

Nitric oxide acts as an extra- and intercellular messenger participating in vascular homeostasis, neurotransmission, and has been associated with various neuropathologies [28]. However, to our knowledge the role of NO in human infant cerebral palsy has not been studied. Some studies have described the role of $\mathrm{NO}$ as protective in various neuropathologies [29] although other authors consider said molecule as pathogenic [30]. Some studies have attributed the appearance of neuropathologies to an increased production of NO by NOS2A causing direct neurotoxicity or vasodilatation and increased cerebral pressure [31]. In this study, we have tried to establish if there is a correlation between NOS2A and the development of infant cerebral palsy in patients with a history of perinatal hypoxia/ischemia by analyzing the association of previously described NOS2A-promoter variants responsible for increased NO production. Furthermore, this is the first study to be carried out in Mexican population and it is also relevant as it provides an insight into the population's mixed race. In vitro experiments using a luciferase gene reporter assay have shown that when there are 13 or 14 microsatellite repeats in the promoter region the transcription rate of NOS2A increases $4 \mathrm{X}$ when induced by oxygen and glucose deprivation; furthermore, IL- $1 \beta$ also increases the transcription of NOS2A by $4 \mathrm{X}$ when there are 13 or 14 microsatellite repeats [19]. We observed an association of the 14 repeatlong allele with the development of cerebral palsy in children with a history of perinatal asphyxia, an increased number of microsatellite repeats is a significant risk factor for severe neurological sequels in Mexican population. We think it is possible that in neonates that suffer perinatal asphyxia whit an APGAR score lower than 7 at 10 minutes the 14-repeat allele is responsible for increasing the level of NO by influencing the transcription rate of NOS2A in infant cerebral palsy patients. NO induces the expression of IL- $1 \beta$, which can up regulate the transcription of NOS2A via stimulation by the (CCTTT)14-repeat microsatellite allele (Figure 3). On the other hand, the presence of the shorter 12-repeat microsatellite allele, possibly downregulating the production of proinflammatory cytokines such as IL- $1 \beta$ in response to perinatal asphyxia, might explain the decreased risk of developing infant cerebral palsy in individuals that have short-form CCTTT microsatellite alleles. Since microsatellites are potentially unstable and of unknown functional relevance [32] the presence of some other yetnot-described mutation in the promoter region or the coding gene

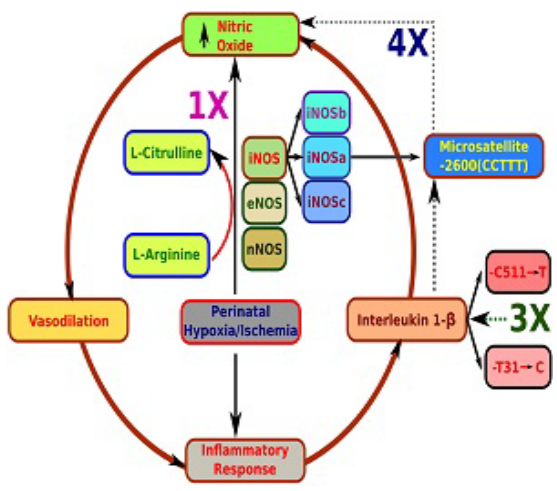

Figure 3: Polymorphic variations in the NOS2a and IL $1 \mathrm{~b}$ genes implicated in $\mathrm{PCl}$ development in patients that suffered perinatal asphyxia. The (CCTTT) microsatellite in the NOS2 gene increase 4 times the NO production. The -511 and -31 polymorphisms in the IL-1b gene increase it's transcription and 3 times the NO production, the haplotypes (CCTTT) 14 $_{14} /-511 \mathrm{~T}$ increase 6 or more times the NO production, conducing to massive neuronal dead by oxidative stress, this condition allows the $\mathrm{PCl}$ development like a sequel in children that suffered perinatal asphyxia. 
Citation: Torres-Merino S, Moreno-Sandoval HN, Thompson-Bonilla DR, Gonzalez-Barrios JA, Leon-Chavez BA, et al. (2015) Association of a Functional Inducible Nitric Oxide Synthase Promoter Variant with Susceptibility to Infantile Cerebral Palsy. J Neurol Disord 3: 248. doi:10.4172/2329-6895.1000248

Page 4 of 4

itself, which might be increasing the susceptibility for developing infant cerebral palsy in Mexican patients with a history of perinatal asphyxia, cannot be ruled out. Nevertheless, our results suggest that the (CCTTT) $\mathrm{n}$ microsatellite in the promoter of the NOS2A gene in patients that suffered perinatal asphyxia could be used immediately after birth to include in the treating an unspecific inhibitor of NOS as L-NGNitroarginine Methyl Ester (L-NAME) or a selective inhibitor for iNOS such as glucocorticoids (dexamethasone) during HIE status, in order to reduce the overproduction of nitric oxide and subsequent oxidative stress, mainly in patients with an expansion of 14 repeats of CCTTT microsatellite, alternatively the expansion could be used to identify patients that require a strong early stimulation program in order to induce synaptic plasticity in the hypoxic/ischemic brain and prevent the development of infant cerebral palsy

\section{Author's Contributions}

STM carried out the diagnosis and treatment of the ICP patients, MRTB and BALCH obtained the blood samples, extracted DNA and genotyped the -2600(CCTTT)n microsatellite, supported the molecular cell biology work. DMF and JAGB conceived the paper, prepared the tables and figures, made the statistical analysis and prepared the final draft of the paper. All authors read and approved the final draft of the manuscript.

\section{Acknowledgements}

The authors thankfully acknowledge FOSIS-CONACYT, México for financial support (Grants FOSIS-69678) and to the General Director ISSSTE, Lic. Miguel Ángel Yunes Linares, and the Head of Hospital Regional "Primero de Octubre" ISSSTE, Dr. Rafael Castillo-Arriaga, for providing the laboratory facilities for the study. Neuropediatric Staff of CRIT and Principal of Mexican-Canadian Institute are acknowledged for providing access to healthy control participants to do the research work. The authors are deeply grateful to the ICP patients and healthy individuals who participated in the study, and their parents that gave the informed consent. Thanks to Dr. Ellis Glazier who edited this English-language text.

\section{References}

1. García-Alix A, Martínez-Biarge M, Diez J, Gayá F, Quero J (2012) Neonatal hypoxic-ischemic encephalopathy: Incidence and prevalence in the first decade of the 21st century. An Pediatr (Barc) 71: 319-26.

2. Rosenbaum P, Paneth N, Leviton A, Goldstein M, Bax M, et al. (2007) A report: the definition and classification of cerebral palsy. Dev Med Child Neurol Suppl 109: 8-14.

3. Tsirikos Al (2010) Development and treatment of spinal deformity in patients with cerebral palsy. Indian J Orthop 44: 148-158.

4. http://www.inegi.gob.mx/inegi/contenidos/espanol/prensa/Contenidos/ estadisticas/2004/nino04.pdf.

5. Johnson A (2000) Cerebral palsies: epidemiology and causal pathways. Archives of Disease in Childhood 83: 279A.

6. O'Shea TM (2008) Diagnosis, treatment, and prevention of cerebral palsy. Clin Obstet Gynecol 51: 816-828.

7. Aly A, Khashaba MT, El-Ayouty M, El-Sayed O, Hasanein BM (2006) IL$1 \beta$ eta, IL-6 and TNF-alpha and outcomes of neonatal hypoxic ischemic encephalopathy. Brain Dev 28: 178-182.

8. Kumar A, Mittal R, Khanna HD, Basu S (2008) Free radical injury and bloodbrain barrier permeability in hypoxic-ischemic encephalopathy. Pediatrics 122 : e722-727.

9. Bredt DS, Hwang PM, Snyder SH (1990) Localization of nitric oxide synthase indicating a neural role for nitric oxide. Nature 347: 768-770.

10. Moncada S, Higgs EA (1991) Endogenous nitric oxide: physiology, pathology and clinical relevance. Eur J Clin Invest 21: 361-374.
11. Kim YM, Bombeck CA, Billiar TR (1999) Nitric oxide as a bifunctional regulator of apoptosis. Circ Res 84: 253-256.

12. Xu W, Liu L, Emson P, Harrington CR, McKeith IG, et al. (2000) The CCTTT polymorphism in the NOS2A gene is associated with dementia with Lewy bodies. Neuroreport 11: 297-299.

13. Chung KK, Thomas B, Li X, Pletnikova O, Troncoso JC, et al. (2004) $\mathrm{S}$-nitrosylation of parkin regulates ubiquitination and compromises parkin's protective function. Science 304: 1328-1331

14. Moncada S, Higgs A (1993) The L-arginine-nitric oxide pathway. N Engl J Med 329: 2002-2012.

15. Warpeha KM, Xu W, Liu L, Charles IG, Patterson CC, et al. (1999) Genotyping and functional analysis of a polymorphic (CCTTT) (n) repeat of NOS2A in diabetic retinopathy. FASEB J 13: 1825-1832.

16. Ohashi J, Naka I, Patarapotikul J, Hananantachai H, Looareesuwan S (2002) Significant association of longer forms of CCTTT Microsatellite repeat in the inducible nitric oxide synthase promoter with severe malaria in Thailand. $J$ Infect Dis 186: $578-581$.

17. Kawaguchi $Y$, Tochimoto A, Hara M, Kawamoto M, Sugiura (2006) NOS2 polymorphisms associated with the susceptibility to pulmonary arterial hypertension with systemic sclerosis: contribution to the transcriptional activity. Arthritis Res Ther 8: R104.

18. Baloira Villar A, Pousada Fernández G, Vilariño Pombo C, Núñez Fernández M, Cifrián Martínez J et al. (2014) CCTTT pentanucleotide repeats in inducible nitric oxide synthase gene expression in patients with pulmonary arterial hypertension. Arch Bronconeumol 50: 141-145.

19. Warpeha KM, Xu W, Liu L, Charles IG, Patterson CC et al. (1999) Genotyping and functional analysis of a polymorphic (CCTTT)(n) repeat of NOS2A in diabetic retinopathy. FASEB J 13: 1825-1832.

20. Johannesen J, Tarnow L, Parving HH, Nerup J, Pociot F (2000) CCTTT-repeat polymorphism in the human NOS2-promoter confers low risk of diabetic nephropathy in type 1 diabetic patients. Diabetes Care 23: 560-562.

21. Benito Pescador D, Isidoro-García M, García-Solaesa V, Pascual de Pedro M Sanz C, et al. (2012) Genetic association study in nasal polyposis. J Investig Allergol Clin Immunol 22: 331-340.

22. Pascual M, Sanz C, Isidoro-García M, Dávila I, Moreno E, et al. (2008) (CCTTT) $\mathrm{n}$ polymorphism of NOS2A in nasal polyposis and asthma: a case-control study. J Investig Allergol Clin Immunol 18: 239-244.

23. Marks-Konczalik J, Chu SC, Moss J (1998) Cytokine-mediated transcriptional induction of the human inducible nitric oxide synthase gene requires both activator protein 1 and nuclear factor kappaB-binding sites. J Biol Chem 273 22201-22208

24. Taylor BS, de Vera ME, Ganster RW, Wang Q, Shapiro RA, et al. (1998) Multiple NF-kappaB enhancer elements regulate cytokine induction of the human inducible nitric oxide synthase gene. J Biol Chem 273: 15148-15156.

25. Jung F, Palmer LA, Zhou N, Johns RA (2000) Hypoxic regulation of inducible nitric oxide synthase via hypoxia inducible factor- 1 in cardiac myocytes. Circ Res 86: 319-325.

26. Krigger KW (2006) Cerebral palsy: an overview. Am Fam Physician 73: 91-100.

27. Dodge NN (2008) Cerebral palsy: medical aspects. Pediatr Clin North Am 55: 1189-1207.

28. Gazzolo D, Abella R, Marinoni E, di lorio R, Volti GL, et al. (2009) New markers of neonatal neurology. J Matern Fetal Neonatal Med 22: 57-61.

29. Keynes RG, Garthwaite J (2004) Nitric oxide and its role in ischaemic brain injury Curr Mol Med 4: 179-191.

30. Aquilano K, Baldelli S, Rotilio G, Ciriolo MR (2008) Role of nitric oxide synthases in Parkinson's disease: a review on the antioxidant and anti-inflammatory activity of polyphenols. Neurochem Res 33: 2416-2426.

31. Maneerat $Y$, Viriyavejakul $P$, Punpoowong $B$, Jones $M$, Wilairatana $P$, et al. (2000) Inducible nitric oxide synthase expression is increased in the brain in fatal cerebral malaria. Histopathology 37: 269-277.

32. Burgner D, Rockett K, Ackerman H, Hull J, Usen S, et al. (2003) Haplotypic relationship between SNP and microsatellite markers at the NOS2A locus in two populations. Genes Immun 4: 506-514. 